\title{
Single-Resistance-Controlled Sinusoidal Oscillator Using Single VD-DIBA
}

\author{
K. L. Pushkar, ${ }^{1}$ D. R. Bhaskar, ${ }^{2}$ and Dinesh Prasad ${ }^{2}$ \\ ${ }^{1}$ Department of Electronics and Communication Engineering, Maharaja Agrasen Institute of Technology, Rohini, \\ New Delhi 110086, India \\ ${ }^{2}$ Department of Electronics and Communication Engineering, F/O Engineering and Technology, Jamia Millia Islamia, \\ Jamia Nagar, New Delhi 110025, India \\ Correspondence should be addressed to D. R. Bhaskar; dbhaskar@jmi.ac.in
}

Received 17 January 2013; Accepted 27 March 2013

Academic Editor: Ali Umit Keskin

Copyright ( $\odot 2013$ K. L. Pushkar et al. This is an open access article distributed under the Creative Commons Attribution License, which permits unrestricted use, distribution, and reproduction in any medium, provided the original work is properly cited.

This paper presents a new single-resistance-controlled sinusoidal oscillator (SRCO). The proposed oscillator employs only one voltage differencing differential input buffered amplifier (VD-DIBA), two resistors, and two grounded capacitors. The proposed configuration offers the following advantageous features: (i) independent control of condition of oscillation and frequency of oscillation, (ii) low active and passive sensitivities, and (iii) a very good frequency stability. The validity of the proposed SRCO has been established by SPICE simulations using $0.35 \mu \mathrm{m}$ MIETEC technology.

\section{Introduction}

Realisation of oscillators and active filters has become important research area in analog circuit design. Recently, various modern active building blocks have been introduced in [1], and VD-DIBA is one of them which is emerging as a very flexible and versatile building block for analog signal processing and has been used earlier for realizing a number of functions. Single-resistance-controlled sinusoidal oscillators (SRCOs) play an important role in control systems, signal processing, communication, and instrumentation and measurement systems [2-4]. SRCOs employing different active building blocks have attracted considerable attention of the researchers due to their several advantages over traditional op-amp-based SRCOs; see [5-15] and the references cited therein. The applications, advantages, and usefulness of VDDIBA have now been recognised in the realisation of firstorder all-pass filter, in simulation of inductors and in the realisation of sinusoidal oscillator [16-18]. However, to the best of the knowledge and belief of the authors, none of the SRCOs using single VD-DIBA has yet been presented in the literature so far. Therefore, the purpose of this paper is to present a new SRCO using a single VD-DIBA along with a bare minimum number of four passive components. The proposed configuration offers (i) independent control of condition of oscillation and frequency of oscillation, (ii) low active and passive sensitivities, and (iii) a very good frequency stability. The workability of the proposed SRCO has been established by SPICE simulations using $0.35 \mu \mathrm{m}$ MIETEC technology.

\section{New Oscillator Configuration}

The schematic symbol and behavioral model of the VD-DIBA are shown in Figures 1(a) and 1(b), respectively. The model includes two controlled sources: the current source controlled by differential voltage $\left(V_{+}-V_{-}\right)$, with the transconductance $g_{m}$, and the voltage source controlled by differential voltage $\left(V_{z}-V_{v}\right)$, with the unity voltage gain. The VD-DIBA can be described by the following set of equations:

$$
\left(\begin{array}{c}
I_{+} \\
I_{-} \\
I_{z} \\
I_{v} \\
V_{w}
\end{array}\right)=\left(\begin{array}{ccccc}
0 & 0 & 0 & 0 & 0 \\
0 & 0 & 0 & 0 & 0 \\
g_{m} & -g_{m} & 0 & 0 & 0 \\
0 & 0 & 0 & 0 & 0 \\
0 & 0 & 1 & -1 & 0
\end{array}\right)\left(\begin{array}{c}
V_{+} \\
V_{-} \\
V_{z} \\
V_{v} \\
I_{w}
\end{array}\right) \text {. }
$$


. MODEL N NMOS $(\mathrm{LEVEL}=3 \quad \mathrm{TOX}=7.9 E-9 \quad \mathrm{NSUB}=1 E 17 \quad$ GAMMA $=0.5827871 \quad \mathrm{PHI}=0.7 \quad \mathrm{VTO}=0.5445549$

DELTA $=0 \quad \mathrm{UO}=436.256147 \quad \mathrm{ETA}=0 \quad \mathrm{THETA}=0.1749684 \quad \mathrm{KP}=2.055786 E-4 \quad \mathrm{VMAX}=8.309444 E 4 \quad \mathrm{KAPPA}=0.2574081$

$\mathrm{RSH}=0.0559398 \quad \mathrm{NFS}=1 E 12 \quad \mathrm{TPG}=1 \quad \mathrm{XJ}=3 E-7 \quad \mathrm{LD}=3.162278 E-11 \quad \mathrm{WD}=7.046724 E-8 \quad \mathrm{CGDO}=2.82 E-10$

$\mathrm{CGSO}=2.82 E-10 \quad \mathrm{CGBO}=1 E-10 \quad \mathrm{CJ}=1 E-3 \quad \mathrm{~PB}=0.9758533 \quad \mathrm{MJ}=0.3448504 \quad \mathrm{CJSW}=3.777852 E-10$

$\mathrm{MJSW}=0.3508721$

.MODEL P PMOS $(\mathrm{LEVEL}=3 \quad$ TOX $=7.9 E-9 \quad \mathrm{NSUB}=1 E 17 \quad$ GAMMA $=0.4083894 \quad \mathrm{PHI}=0.7 \quad \mathrm{VTO}=-0.7140674$

$\mathrm{DELTA}=0 \quad \mathrm{UO}=212.2319801 \quad \mathrm{ETA}=9.999762 E-4 \quad \mathrm{THETA}=0.2020774 \mathrm{KP}=6.733755 E-5 \quad \mathrm{VMAX}=1.181551 E 5$

$\mathrm{KAPPA}=1.5 \quad \mathrm{RSH}=30.0712458 \quad \mathrm{NFS}=1 E 12 \quad \mathrm{TPG}=-1 \quad \mathrm{XJ}=2 E-7 \quad \mathrm{LD}=5.000001 E-13 \quad \mathrm{WD}=1.249872 E-7$

$\mathrm{CGDO}=3.09 E-10 \quad \mathrm{CGSO}=3.09 E-10 \quad \mathrm{CGBO}=1 E-10 \quad \mathrm{CJ}=1.419508 E-3 \quad \mathrm{~PB}=0.8152753 \quad \mathrm{MJ}=0.5$

$\mathrm{CJSW}=4.813504 \mathrm{E}-10 \mathrm{MJSW}=0.5)$

Box 1

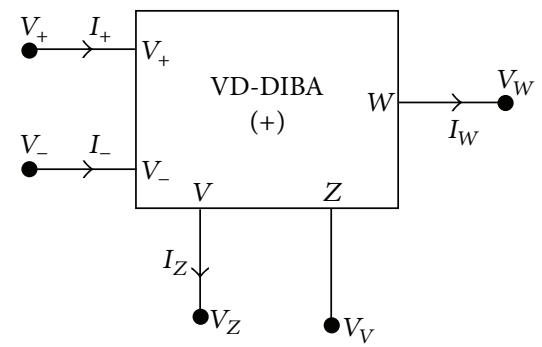

(a)

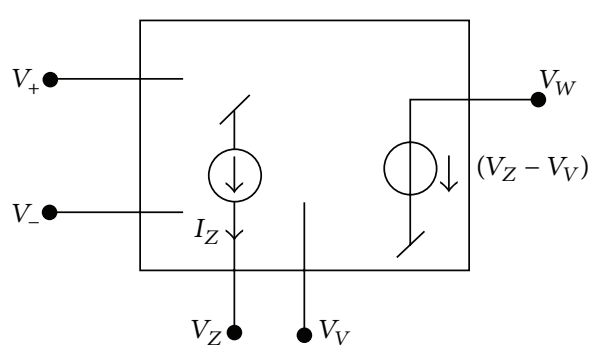

(b)

Figure 1: (a) Schematic symbol and (b) behavioural model of VD-DIBA.

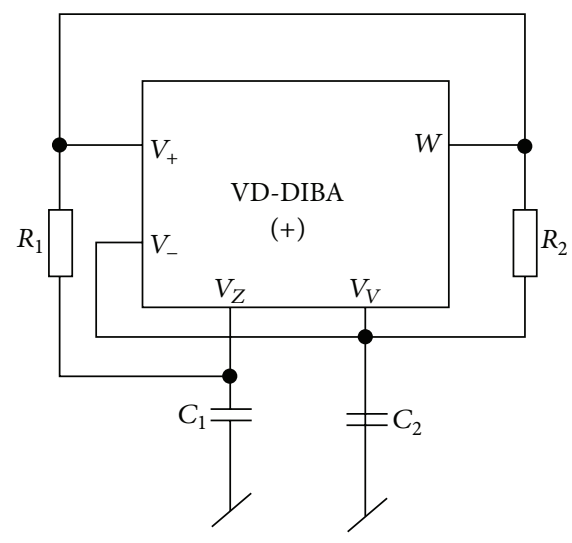

FIgURE 2: The proposed configuration.

A routine circuit analysis of Figure 2 yields the following characteristic equation:

$$
s^{2} C_{1} C_{2} R_{1} R_{2}+s R_{1}\left\{2 C_{1}-C_{2} g_{m} R_{2}\right\}+1=0 .
$$

Thus, the condition of oscillation (CO) and frequency of oscillation (FO) are given by

$$
\text { CO: }\left\{2 C_{1}-C_{2} g_{m} R_{2}\right\} \leq 0 \text {, }
$$

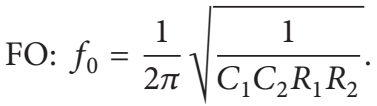

TABLE 1

\begin{tabular}{lc}
\hline Transistor & $W / L(\mu \mathrm{m})$ \\
\hline $\mathrm{M}_{1}-\mathrm{M}_{6}$ & $14 / 1$ \\
$\mathrm{M}_{7}-\mathrm{M}_{9}$ & $14 / 0.35$ \\
$\mathrm{M}_{10}-\mathrm{M}_{18}$ & $4 / 1$ \\
$\mathrm{M}_{19}-\mathrm{M}_{22}$ & $7 / 0.35$ \\
\hline
\end{tabular}

Therefore, it is seen that FO is independently controllable by resistor $R_{1}$ and CO is controlled by $g_{m}$.

\section{Frequency Stability Analysis}

Frequency stability may be considered to be an important figure of merit of an oscillator. The frequency stability factor is defined as $S^{F}=d \phi(u) / d u$, where $u=\omega / \omega_{0}$ is the normalized frequency, and $\phi(u)$ represents the phase function of the open loop transfer function of the oscillator circuit, with $C_{1}=C_{2}=$ $C, R_{2}=2 R, R=1 / g_{m}$, and $R_{1}=R / n ; S^{F}$ for the proposed SRCO is found to be

$$
\begin{aligned}
S^{F} & =\sqrt{2 n}\left\{\frac{-2 n}{2 n+1}\right\} \\
& \approx-\sqrt{2 n} \text { for } n \gg 1 .
\end{aligned}
$$

Thus, for larger values of $n$, the oscillator enjoys a very good frequency stability. 


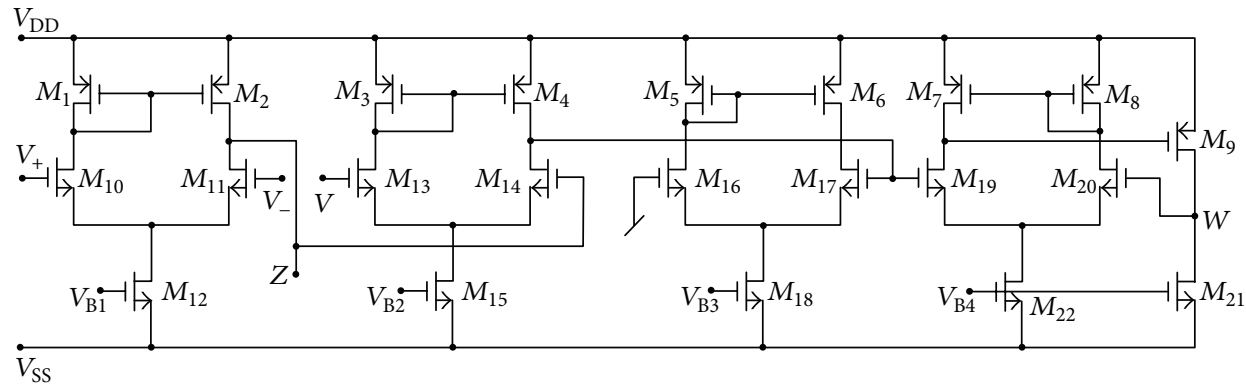

FIgURE 3: Proposed CMOS implementation of VD-DIBA; $V_{\mathrm{DD}}=-V_{\mathrm{SS}}=2 \mathrm{~V}, V_{\mathrm{B} 1}=-0.44 \mathrm{~V}, V_{\mathrm{B} 2}=V_{\mathrm{B} 3}=-0.22 \mathrm{~V}$, and $V_{\mathrm{B} 4}=-0.9 \mathrm{~V}$.

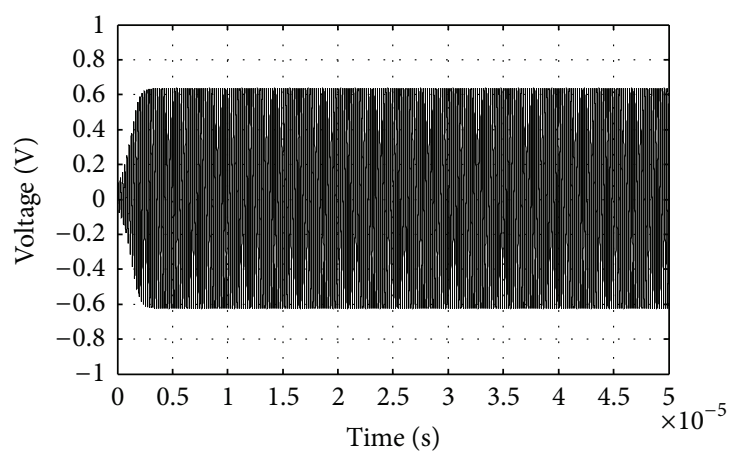

(a)

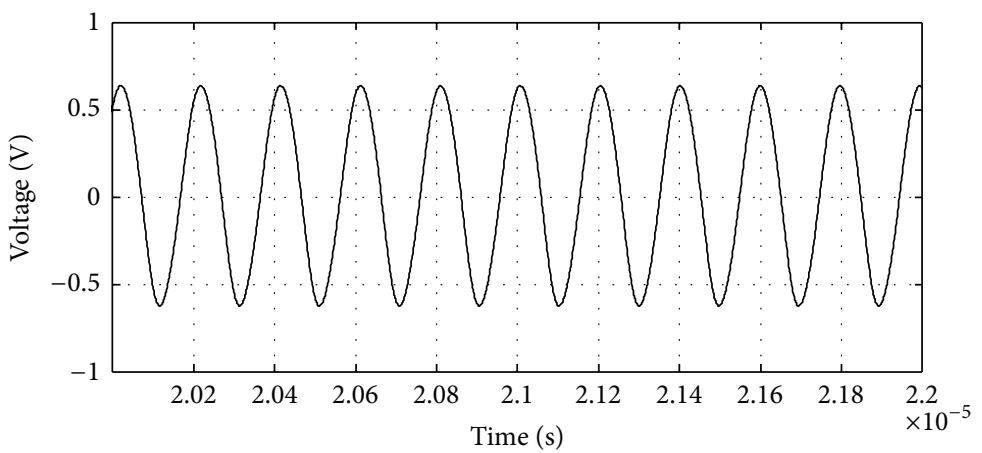

(b)

Figure 4: (a) Transient output waveform. (b) Steady state response of the output.

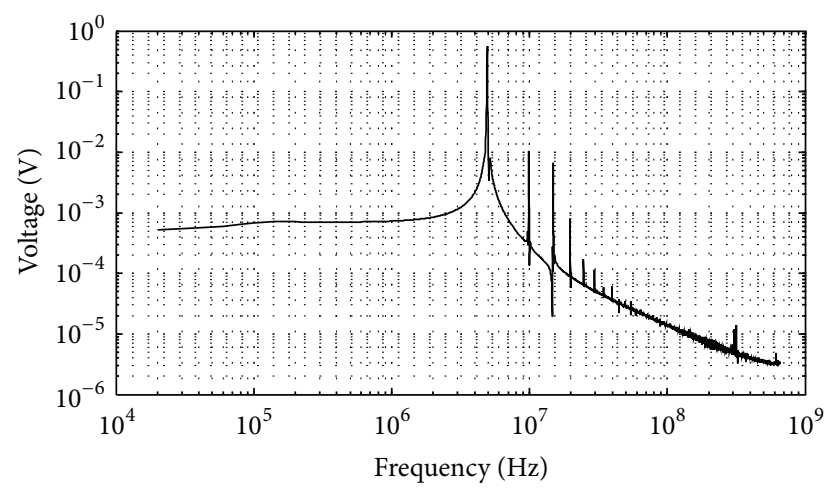

Figure 5: Simulation result of the output spectrum.

\section{Nonideal Analysis and Sensitivity Performance}

Let $R_{Z}$ and $C_{Z}$ denote the parasitic resistance and parasitic capacitance of the $Z$-terminal of the VD-DIBA. Taking the nonidealities into account, namely, the voltage of $W$-terminal $V_{W}=\left(\beta^{+} V_{Z}-\beta^{-} V_{V}\right)$, where $\beta^{+}=1-\varepsilon_{p}\left(\varepsilon_{p} \ll 1\right)$ and $\beta^{-}=1-\varepsilon_{n}\left(\varepsilon_{n} \ll 1\right)$ denote the voltage tracking errors of $Z$ terminal and $V$-terminal of the VD-DIBA, respectively, then the expressions for $\mathrm{CO}$ and $\mathrm{FO}$ become

$$
\text { CO: } \begin{aligned}
\{ & \left(\beta^{-}+1\right)\left(C_{1}+C_{z}\right) \\
& \left.-C_{2}\left\{\left(\beta^{+}-1\right) \frac{R_{2}}{R_{1}}+\beta^{+} g_{m} R_{2}+\frac{R_{2}}{R_{z}}\right\}\right\} \leq 0,
\end{aligned}
$$

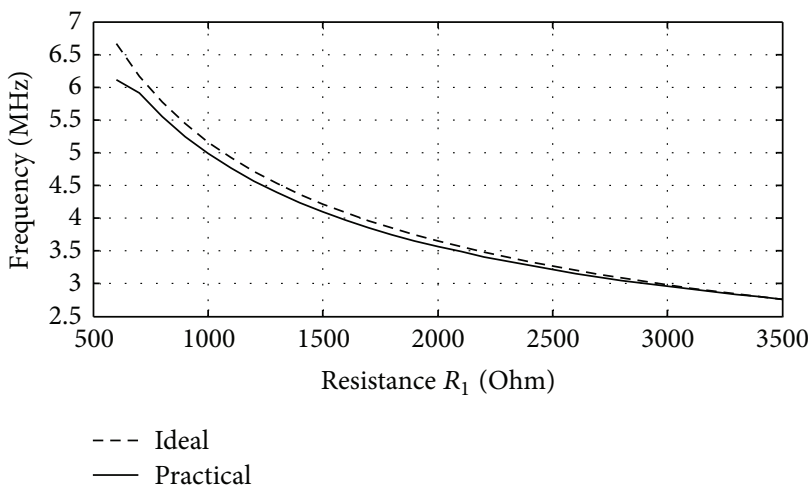

Figure 6: Variation of frequency with resistance $R_{1}$.

FO: $\omega_{0}=\sqrt{\frac{\left\{\beta^{+}-\left(\beta^{-}+1\right)\left(\beta^{+}-1\right)\right\}+\left(\beta^{-}+1\right)\left(R_{1} / R_{Z}\right)}{\left(C_{1}+C_{Z}\right) C_{2} R_{1} R_{2}}}$.

The left-hand side of (3) with the component values shown in Section 4 turns out to be -0.812 which is in accordance with $(3)(<0)$. On the other hand, when left-hand side of $(6)$ is calculated using the components and parasitic values in Section 4, it turns out to be -0.7992 . It is therefore seen that both values are quite close from these numerical examples; it can be inferred that by considering $C_{1} \gg C_{Z}$, and $R_{1}, R_{2} \ll$ $R_{Z}$, (6) becomes $\left\{2 C_{1}-C_{2} R_{2}\left(g_{m}+1 / R_{z}\right)\right\} \leq 0$ which shows that (6) is almost the same as (3). 
TABLE 2

\begin{tabular}{lccccc}
\hline Reference & Active component(s) & Grounded capacitors & Floating capacitors & Resistors & CO and FO independently controllable \\
\hline$[5]$ & 1 & 1 & 1 & 3 & Yes \\
{$[6]$} & 1 & 1 & 1 & 3 & Yes \\
{$[7]$} & 2 & 2 & 0 & 3 & Yes \\
{$[8]$} & 1 & 1 & 1 & 3 & Yes \\
{$[9]$} & 1 & 2 & 0 & 4 & No \\
{$[10]$} & 1 & 2 & 0 & 3 & Yes \\
{$[11]$} & 1 & 2 & 0 & $3 / 2$ & Yes \\
{$[12]$} & 1 & 1 (virtually grounded) & 1 & 3 & Yes (only in second topology of Table 1) \\
{$[13]$} & 1 & 1 (virtually grounded) & 1 & 3 & No \\
{$[14]$} & 1 & 1 & 1 & 2 & Yes \\
{$[18]$} & 2 & 2 & 0 & 1 & Yes \\
{$[15]$} & 1 & 2 & 0 & 2 & Yes \\
Proposed & 1 & 2 & 0 & 2 & Yes \\
\hline
\end{tabular}

Its active and passive sensitivities can be found as

$$
\begin{gathered}
S_{C_{1}}^{\omega_{0}}=-\frac{1}{2} \frac{C_{1}}{C_{1}+C_{Z}}, \\
S_{C_{2}}^{\omega_{0}}=-\frac{1}{2}, \\
S_{C_{Z}}^{\omega_{0}}=-\frac{1}{2} \frac{C_{Z}}{C_{1}+C_{Z}}, \\
S_{R_{1}}^{\omega_{0}}=-\frac{1}{2\left\{1+\left(\left(\beta^{-}+1\right)\left(R_{1} / R_{Z}\right)\right) /\left(\beta^{+}-\left(\beta^{-}+1\right)\left(\beta^{+}-1\right)\right)\right\}}, \\
S_{R_{Z}}^{\omega_{0}}=-\frac{1}{2 R_{Z}} \frac{S_{R_{2}}^{\omega_{0}}=-\frac{1}{2},}{\left\{\beta^{+}-\left(\beta^{-}+1\right)\left(\beta^{+}-1\right)+\left(\beta^{-}+1\right) R_{1}\right\}}, \\
S_{\beta^{+}}^{\omega_{0}}=\frac{1}{2} \frac{\beta^{+}\left\{\left(\beta^{-}+1\right)\left(R_{1} / R_{Z}\right)-\beta^{-}\right\}}{\left\{1+\left(\beta^{+}-1\right)\left(R_{1} / R_{Z}-\beta^{-}\right)\right\}}, \\
S_{\beta^{-}}^{\omega_{0}}=\frac{1}{2} \frac{\beta^{-}\left\{R_{1} / R_{Z}-\left(\beta^{+}-1\right)\right\}}{\left\{1+\left(\beta^{+}-1\right)\left(R_{1} / R_{Z}-\beta^{-}\right)\right\}} .
\end{gathered}
$$

In the ideal case, the various sensitivities of $\mathrm{FO}$ with respect to $R_{1}, R_{2}, C_{1}$, and $C_{2}$ are found to be

$$
S_{R_{1}}^{\omega_{0}}=S_{R_{2}}^{\omega_{0}}=S_{C_{1}}^{\omega_{0}}=S_{C_{2}}^{\omega_{0}}=-\frac{1}{2}
$$

Considering the typical values of various parasitic, for example, $C_{z}=0.81 \mathrm{pF}, R_{z}=53 \mathrm{k} \Omega$, and $\beta^{+}=\beta^{-}=1$ along with $C_{1}=C_{2}=0.01 \mathrm{nF}, R_{1}=1 \mathrm{k} \Omega$, and $R_{2}=9.5 \mathrm{k} \Omega$, the various sensitivities are found to be $S_{C_{1}}^{\omega_{0}}=-0.4625, S_{C_{2}}^{\omega_{0}}=$ $-0.5, S_{C_{Z}}^{\omega_{0}}=-0.03747, S_{R_{1}}^{\omega_{0}}=-0.3681, S_{R_{2}}^{\omega_{0}}=-0.5, S_{R_{Z}}^{\omega_{0}}=$ $-0.132, S_{\beta^{+}}^{\omega_{0}}=-0.17925$, and $S_{\beta^{-}}^{\omega_{0}}=0.0896$ which are all low.

\section{Simulation Results}

To confirm theoretical analysis, the proposed SRCO was simulated using CMOS VD-DIBA (as shown in Figure 3 ). The passive elements were selected as $C_{1}=C_{2}=0.01 \mathrm{nF}, R_{1}=$ $1 \mathrm{~K} \Omega$, and $R_{2}=9.5 \mathrm{~K} \Omega$. The transconductance of VD-DIBA was controlled by bias voltage $V_{\mathrm{B} 1}$. PSPICE-generated output waveforms indicating transient and steady state responses are shown in Figures 4(a) and 4(b), respectively. These results, thus, confirm the validity of the proposed configuration. Figure 5 shows the output spectrum, where the total harmonic distortion (THD) is found to be $2.77 \%$. Figure 6 shows the variation of frequency with resistance $R_{1}$. A comparison with other previously known SRCOs using different active building blocks has been given in Table 2 .

The CMOS VD-DIBA is implemented using $0.35 \mu \mathrm{m}$ MIETEC real transistor model which is listed in Box 1.

Aspect ratios of transistors used in Figure 3 are given in Table 1.

\section{Conclusions}

A new application of a recently introduced VD-DIBA in the realisation of SRCO has been proposed. The proposed configuration employs a minimum possible number of passive elements (namely, two resistors and two grounded capacitors) and yet offers independent control of FO through the resistor $R_{1}$ and CO through the transconductance $g_{m}$ (hence, the circuit enjoys the electronic control of $\mathrm{CO}$ ), low active and passive sensitivities, and a very good frequency stability. This paper thus added a new application circuit to the existing repertoire of VD-DIBA-based application circuits.

\section{References}

[1] D. Biolek, R. Senani, V. Biolkova, and Z. Kolka, "Active elements for analog signal processing: classification, review, and new proposals," Radioengineering, vol. 17, no. 4, pp. 15-32, 2008.

[2] R. Senani, "New types of sine wave oscillators," IEEE Transactions on Instrumentation and Measurement, vol. 34, no. 3, pp. 461-463, 1985. 
[3] R. Senani and D. R. Bhaskar, "Single op-amp sinusoidal oscillators suitable for generation of very low frequencies," IEEE Transactions on Instrumentation and Measurement, vol. 40, no. 4, pp. 777-779, 1991.

[4] D. R. Bhaskar and R. Senani, "New CFOA-based singleelement-controlled sinusoidal oscillators," IEEE Transactions on Instrumentation and Measurement, vol. 55, no. 6, pp. 2014-2021, 2006.

[5] V. K. Singh, R. K. Sharma, A. K. Singh, D. R. Bhaskar, and R. Senani, "Two new canonic single-CFOA oscillators with single resistor controls," IEEE Transactions on Circuits and Systems II, vol. 52, no. 12, pp. 860-864, 2005.

[6] S. Celma, P. A. Martinez, and A. Carlosena, "Minimal realisation for single resistor controlled sinusoidal oscillator using single CCII," Electronics Letters, vol. 28, no. 5, pp. 443-444, 1992.

[7] D. R. Bhaskar and R. Senani, "New current-conveyor-based single-resistance-controlled/voltage-controlled oscillator employing grounded capacitors," Electronics Letters, vol. 29, no. 7, pp. 612-614, 1993.

[8] C. T. Lee and H. Y. Wang, "Minimum realisation for FTFNbased SRCO,” Electronics Letters, vol. 37, no. 20, pp. 1207-1208, 2001.

[9] D. R. Bhaskar, "Grounded-capacitor SRCO using only one PFTFN,” Electronics Letters, vol. 38, no. 20, pp. 1156-1157, 2002.

[10] S. S. Gupta and R. Senani, "Grounded-capacitor current-mode SRCO: novel application of DVCCC," Electronics Letters, vol. 36, no. 3, pp. 195-196, 2000.

[11] V. Aggarwal, S. Kilinç, and U. Çam, "Minimum component SRCO and VFO using a single DVCCC," Analog Integrated Circuits and Signal Processing, vol. 49, no. 2, pp. 181-185, 2006.

[12] S. Özcan, A. Toker, C. Acar, H. Kuntman, and O. Çiçekoglu, "Single resistance-controlled sinusoidal oscillators employing current differencing buffered amplifier," Microelectronics Journal, vol. 31, no. 3, pp. 169-174, 2000.

[13] U. Çam, "A novel single-resistance-controlled sinusoidal oscillator employing single operational transresistance amplifier," Analog Integrated Circuits and Signal Processing, vol. 32, no. 2, pp. 183-186, 2002.

[14] D. Prasad, D. R. Bhaskar, and A. K. Singh, "Realisation of singleresistance-controlled sinusoidal oscillator: a new application of the CDTA," WSEAS Transactions on Electronics, vol. 5, no. 6, pp. 257-259, 2008.

[15] D. Biolek, A. U. Keskin, and V. Biolkova, "Grounded capacitor current mode single resistance-controlled oscillator using single modified current differencing transconductance amplifier," IET Circuits, Devices and Systems, vol. 4, no. 6, pp. 496-502, 2010.

[16] D. Biolek and V. Biolkova, "First-order voltage-mode allpass filter employing one active element and one grounded capacitor," Analog Integrated Circuits and Signal Processing, vol. 65, no. 1, pp. 123-129, 2010.

[17] D. Prasad, D. R. Bhaskar, and K. L. Pushkar, "Realization of new electronically controllable grounded and floating simulated inductance circuits using voltage differencing differential input buffered amplifiers," Active and Passive Electronic Components, vol. 2011, Article ID 101432, 8 pages, 2011.

[18] D. Prasad, D. R. Bhaskar, and K. L. Pushkar, "Electronically controllable sinusoidal oscillator employing CMOS VD-DIBAs," ISRN Electronics, vol. 2013, Article ID 823630, 6 pages, 2013. 

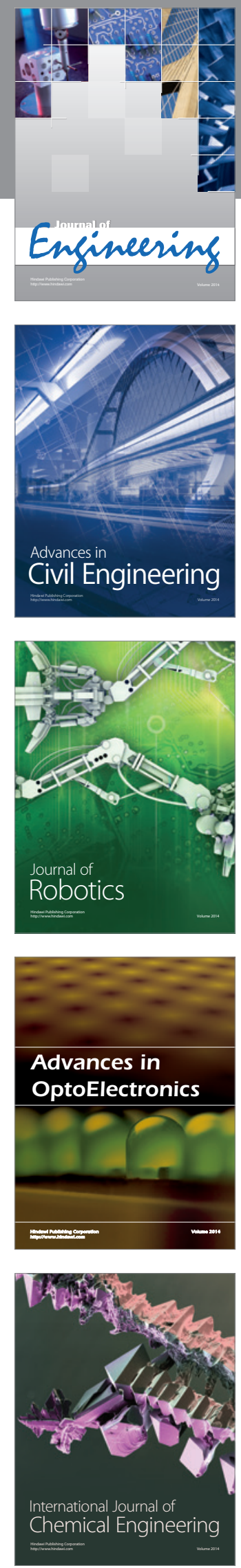

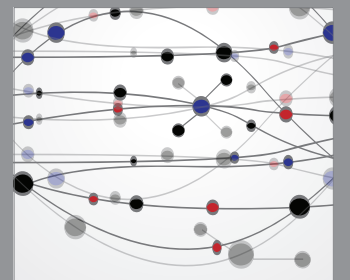

The Scientific World Journal
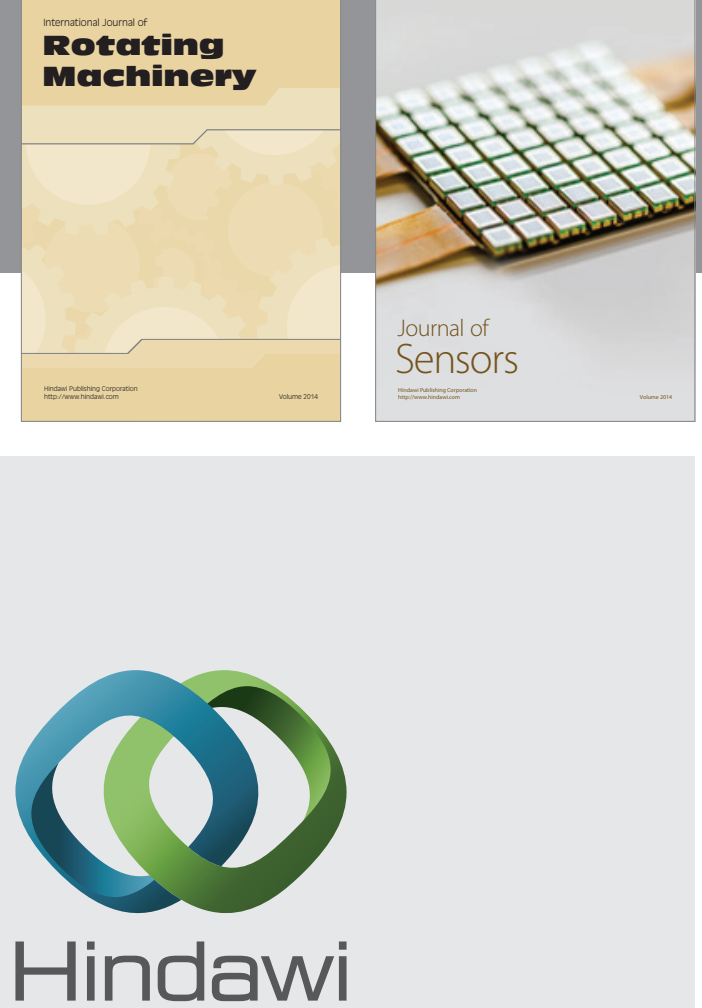

Submit your manuscripts at http://www.hindawi.com
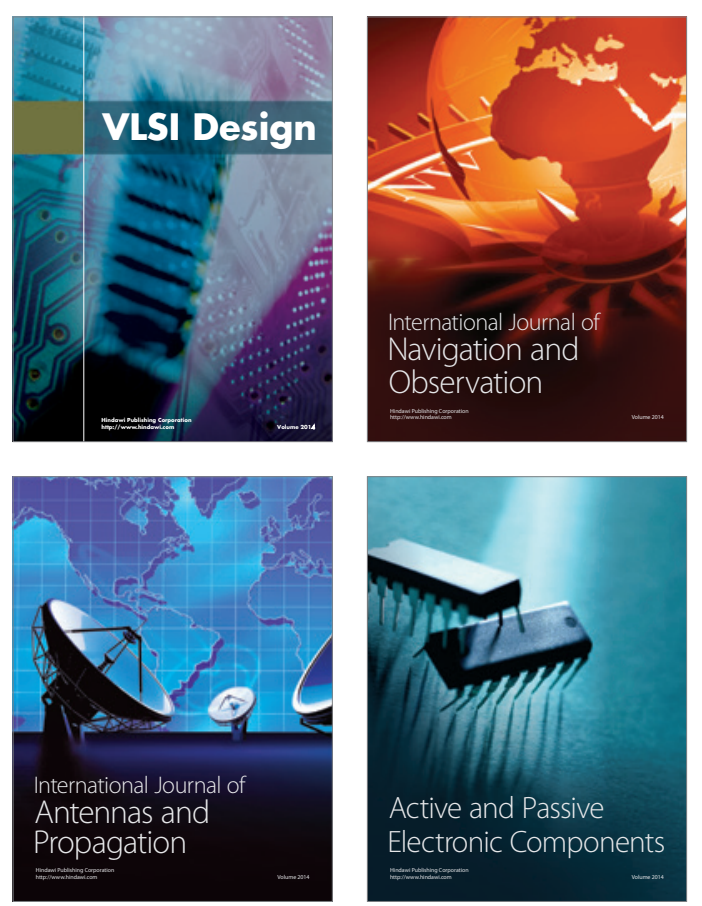
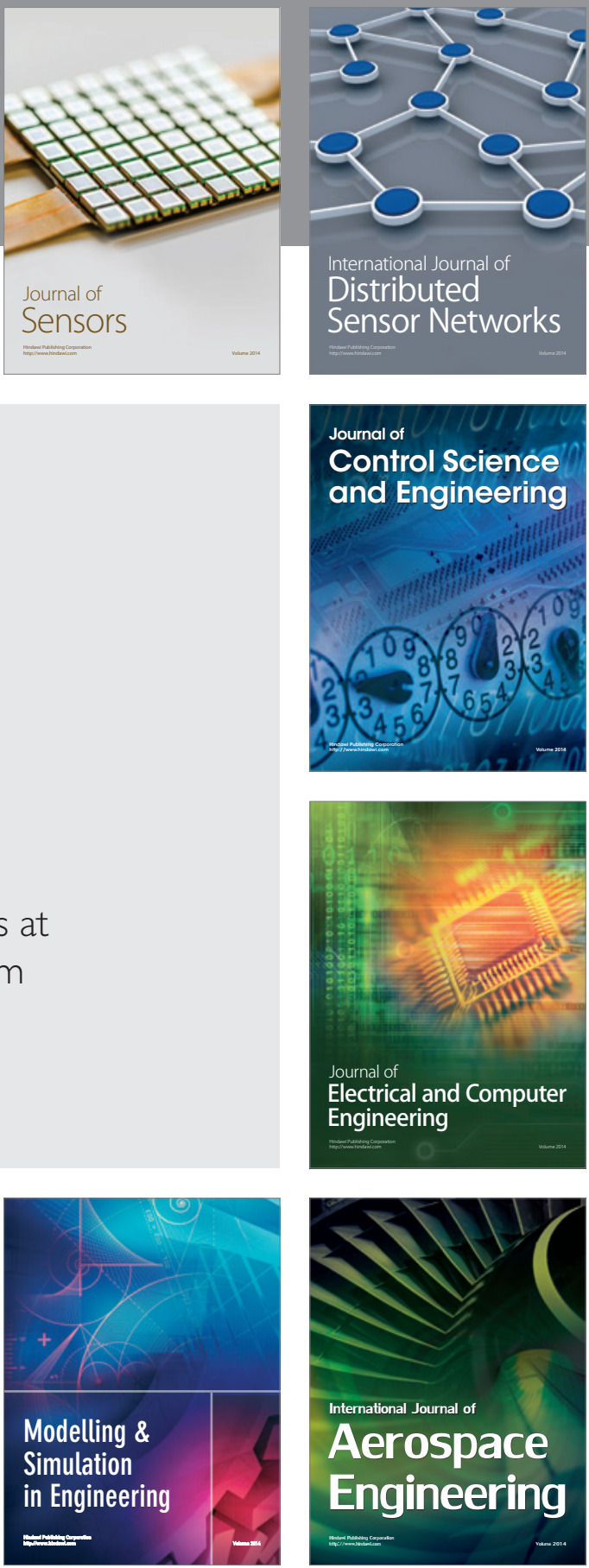

Journal of

Control Science

and Engineering
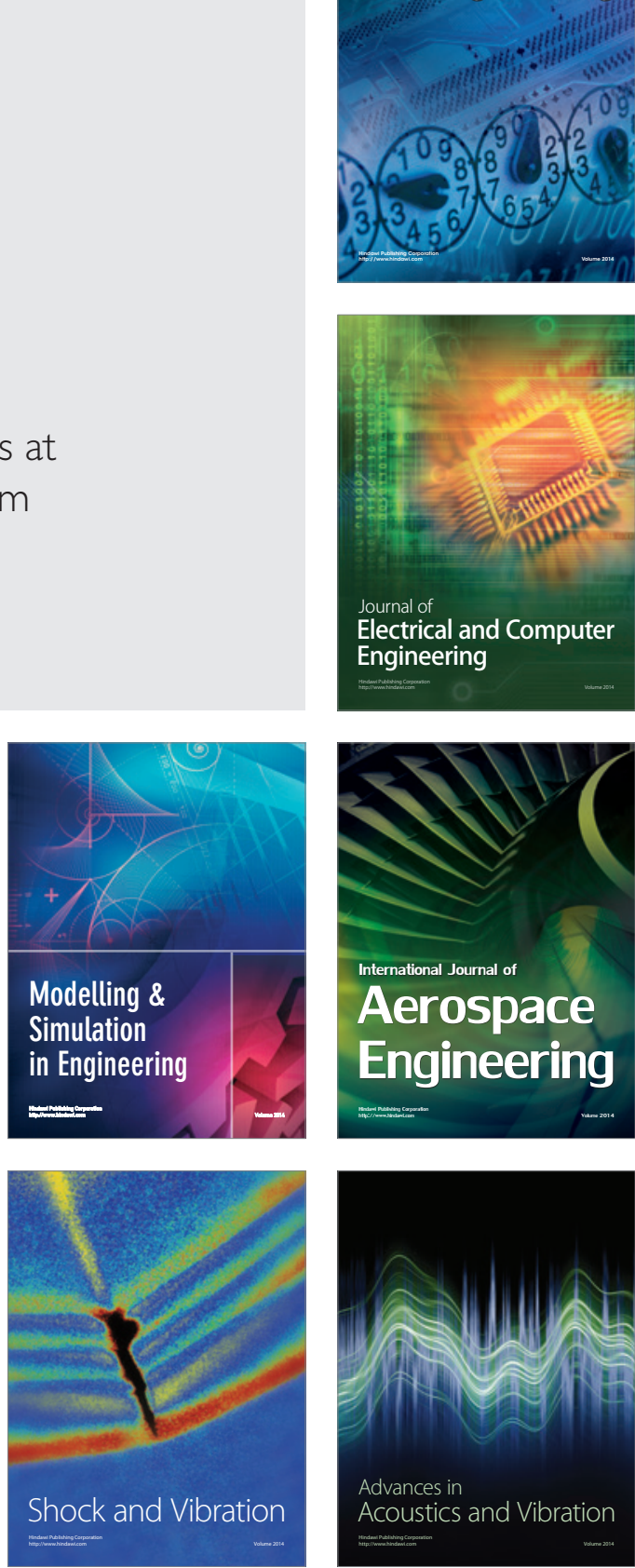